\title{
Genç Yetişkinlerde Fiziksel Aktivite ve Bilişsel Performans Arasındaki İlişkinin İncelenmesi
}

DOI: 10.26466/opus. 932629

\author{
$*$ \\ Bağdat Tekkuș* \\ * Yl. Öğr., İstanbul Medipol Üniversitesi, Sağlık Bilimleri Enstitüsü, İstanbul/Türkiye \\ E-Posta: bagdattekkus@gmail.com \\ ORCID:0000-0001-9719-8321
}

\section{Öz}

Fiziksel aktivitenin sağlığın birçok alanında kanıta dayalı olumlu etkileri belirlenmiş olup dikkat hafiza ve yürütücü işlevler gibi kognitif fonksiyonlar üzerindeki etkileri araştırllmaktadır. Bu çalışma üniversite öğrencilerinin fiziksel aktivite seviyeleri ile kognitif performansları arasındaki ilişkiyi incelemek amacıyla yapılmıştır. Bu amaç doğrultusunda yaşları 18-25 aralı̆̆nda değişen 83 kişi ile testler yürütülmüş̧ür. Fiziksel aktivite seviyelerinin tespitinde Uluslararası Fiziksel Aktivite Kısa Anketi (International Physical Activity Questionnare-IPAQ), kognitif performans seviyelerini belirlemede yürütücü işlevleri içeren Stroop Testi TBAG Formu kullanılmış ayrıca demografik bilgiler kaydedilmiştir. Tüm analizlerde istatistiksel anlamlllık $p<0.05$ olarak kabul edilmiştir. ANOVA testi sonucunda Stroop etkisi fenomeni uyumsuz koşulda tepki sürelerinin anlaml olarak gecikmesi ile gözlemlenmiştir. Kontrol ve uyumlu koşulda tepki süreleri uyumsuz koşula göre daha hızlıdır. Fiziksel aktivitenin Stroop efekte etkisi anlaml bulunmamıştır. MET ile Stroop etkisi arasındaki ilişkiye bakıldığında MET arttıkça Stroop etkisinin azalma eğilimi gösterdiği gözlemlense de, bu ilişki anlamlı değildir. Çalısmamızda üniversite öğrencilerinin toplam fiziksel aktivite seviyeleri ile kognitif performansları arasında doğrusal bir ilişki tespit edilememiştir. Daha fazla sayıda katılımonın dahil edildiğ $i$ daha ileri araştırmalara ihtiyaç vardır.

Anahtar Kelimeler: Genç Yetişkin, Fiziksel Aktivite, Bilişsel Performans. 


\title{
Investigation of the Relationship between Physical Activity and Cognitive Performance in Young Adults
}

\begin{abstract}
Evidence-based positive effects of physical activity on many areas of health have been determined, and its effects on cognitive functions such as attention, memory and executive functions are investigated. This study was conducted to examine the relationship between university students' physical activity levels and their cognitive performance. For this purpose, tests were conducted with 83 people whose ages ranged from 18-25. The International Physical Activity Questionnare (IPAQ) was used to determine physical activity levels, and the Stroop Test TBAG Form, which includes executive functions to determine cognitive performance levels, and demographic information was recorded. IBM SPSS 21 package program was used in the data analysis of the study. Statistical significance was accepted as $p<0.05$ in all analyzes. As a result of the ANOVA test, the Stroop effect phenomenon was observed with a significant delay in reaction times in the incompatible condition. Response times in control and adaptive condition are faster than in non-compliant conditions. The effect of physical activity on the stroop effect is not significant. Considering the relationship between BAT and Stroop effect, it is observed that as the MET increases, the Stroop effect tends to decrease, but this relationship is not significant. In our study, no linear relationship was found between university students' total physical activity levels and their cognitive performance. Further research is needed, involving larger numbers of participants.
\end{abstract}

Keywords: Young Adults, Physical Activity, Cognitive Performance. 


\section{Giriş}

Fiziksel aktivite, "bazal metabolizma seviyesi üzerinde enerji harcamasıyla kas ve eklem hareketi gerektiren, kalp ve solunum hızını arttıran, farklı şiddetlerde yapılabilen ve yorgunlukla sonuçlanan bedensel hareketler" olarak tanımlanmaktadır (Ardiç, 2014; Savci vd., 2006). Modern yaşam ve ilerleyen teknolojik gelişmeler hayatı kolaylaştırırken, inaktiviteyi artırmakta, egzersiz ve spor yapmama gençler de dahil toplumun her kesiminde fiziksel aktivite seviyesini azaltmaktadır. Fiziksel aktivite yetersizliğine bağlı olarak ilerleyen yaşla birlikte kardiyovasküler hastalıklar, obezite, Tip II diyabet, hipertansiyon, osteoartroz, osteoporoz ve bazı kanser türlerini de içeren hastalık riskleri artmakta, bilişsel yetersizlikler gelişmektedir. Ülkemizde fiziksel aktivite yapılma oranı \%25'i geçmemektedir (Ardiç, 2014). Çevreden gelen uyarıların algılanarak kortekse gelmesi ile davranıs, ve hareketlerin değștirilerek cevaplanma süreci kognisyon ve bu sürecte yer alan beceriler ise kognitif fonksiyonlar olarak adlandirılır. Bu fonksiyonlar; hafıza, hatırlama, oryantasyon, gibi temel becerilerinin yanısıra dikkat, problem çözme,karar verme gibi daha üst yönetimsel fonksiyonları da içerir (Bamidis vd., 2014).

Fiziksel aktivitenin sağlığın birçok alanının yanısıra dikkat hafıza ve yürütücü işlevler gibi kognitif fonksiyonlar üzerinde olumlu etkilerini bildiren çalışmalar mevcuttur (Wang ve Biddle, 2001). Fiziksel aktivite ve kognitif fonksiyon ilişkisi açısından daha çok çocuk ve yaşlılarla yapılan araştırmalar mevcut olup genç erişkinlerle yapılan çalışmalar azdır (Kargun vd., 2016). Literatürde fiziksel olarak aktif bir yaşam sürmenin ve düzenli yapılan egzersizlerin kronik hastalık riskinin azaltılmasının yanısıra yaşamın her döneminde fiziksel ve psikolojik sağlığa olumlu etkileri ve kognitif işlevlerin geliştirilmesi açısından her yas, grubunda önemi belirtilmektedir (Ardiç, 2014; Kargun vd., 2016; Wang ve Biddle, 2001). Fiziksel aktivitenin serebral korteks ve hipokampüste olumlu etkiler oluşturarak, demans ve bilişsel bozulma olasılığını azalttığı ve bireyin daha iyi bilişsel performans gösterdiğini belirten araştırmalar mevcuttur (Acevedo ve Loewenstein, 2007; Ergun, 2013; Kargun vd., 2016). Ancak fiziksel aktivite seviyesi ile kognitif fonksiyon arasında korelasyonla ilgili çalışmalar bilişsel fonksiyonun test edilen yönü ve test yöntemi açısında da 
farklılıklar göstermektedir (Etnier vd., 2006; Padulo vd., 2019). Son dönemlerde fiziksel aktivite düzeyi ile kognitif fonksiyonun bir göstergesi sayılan akademik bașarı konusunda yapılan araştırmalar önem kazanmaya başlamıştır. İtalya'da ilkokul öğrencilerinin fiziksel aktivite ve okul başarısı arasında güçlü bir korelasyon olduğu vurgulanırken sekizinci sınıf öğrencileriyle yapılan başka bir çalışma da zayıf bir ilişki bildirilmiştir (Bilgin vd., 2020; Padulo vd., 2019). Bu çalışmanın amacı 18-25 yaş arası üniversite öğrencilerinin fiziksel aktivite seviyeleri ile kognitif performansları arasındaki korelasyonun ortaya çıkarılması ve genç nüfusun çoğunluğu oluşturduğu ülkemizde fiziksel aktivite konusunda toplumsal bilinci geliştirmek eğitim hayatında başarıyı destekleyen bir unsur olarak da fiziksel aktiviteyi ön plana çıkarmak ve bu konuda araştırmaları teşvik etmektir.

\section{Yöntem}

\section{Örneklem}

Araştırmaya yaşları 18-25 arasinda değişen, 55'i kadın ve 28'i erkek olmak üzere 83 kişi gönüllü olarak katılmıştır. Katılımcıların cinsiyetleri ve yaş aralıkları Tablo 1'de gösterilmiştir.

Tablo 1. Katılımcılarn fiziksel aktivite miktarına göre cinsiyet dağılımları

\begin{tabular}{lll}
\hline Aktivite & Cinsiyet & (n) \\
\hline \multirow{2}{*}{ Düşük } & Erkek & 10 \\
& Kadın & 25 \\
Orta & Erkek & 15 \\
& Kadın & 24 \\
\multirow{2}{*}{ Yüksek } & Erkek & 3 \\
& Kadın & 6 \\
& Toplam & 83 \\
\hline
\end{tabular}

\section{Uluslararası Fiziksel Aktivite Anketi (UFAA)}

15-65 yas, aralığndaki katılımcıların fiziksel aktivite düzeylerini belirlemek amacıyla Craig ve arkadaslari (2003) tarafından geliștirilmiștir. UFAA'nın Türkiye'de geçerlilik ve güvenilirlik çalışması Öztürk (2005) tarafından yapılmıștır. Uluslararası Fiziksel Aktivite Anketi Kısa 
Formunda 7 soru bulunmaktadır. Son 7 gün içerisinde; buitün aktivitelerin degerlendirilmesinde her bir aktivitenin tek seferde en az $10 \mathrm{dk}$ yapılıyor olması ölçüt alınmaktadır. Bireyin şiddetli, orta dereceli aktiviteleri ve yürüme süreleri sorgulanarak harcanan zaman belirlenmektedir.

Ankette katılımcılara son haftada kaç gün ve her bir gün için ne kadar süre ile ağır fiziksel aktiviteler (ağırlık kaldırma gibi), orta yoğunlukta fiziksel aktiviteler (koşma gibi) ya da hafif düzeyde fiziksel aktivitiler gerçekleştirdikleri sorulmuştur. Bu ölçü puanlanırken Metabolic Equivalent of Task (MET) kullanılmıştır. MET tüketilen oksijen miktarına işaret eder ve istirahat halinde iken her kişi bir kg.başına bir dakikada 3,5 $\mathrm{ml}$ oksijen tüketmektedir. MET katsayısı hafif yoğunluktaki fiziksel aktivitelerde 3,3 ml oksijen, orta yoğunluktaki fiziksel aktivitelerde $4 \mathrm{ml}$ oksijen ve yüksek yoğunluktaki fiziksel aktivitilerde $8 \mathrm{ml}$ oksijen olarak belirlenmiştir. Her bir katılımcının bir haftalık zaman dilimi içinde yaptığı fiziksel aktivitelerin süresi MET katsayısı ile çarpılmış ve katılımcıların MET değerleri saptanmıştır. $600 \mathrm{ml}$ oksijenden az miktarda MET puanı olan katılımcılar fiziksel aktivite seviyesi düşük, 600 ile $3000 \mathrm{ml}$ arası olan katılımcılar fiziksel aktive seviyesi orta ve $3000 \mathrm{ml}^{\prime}$ den fazla olan katılımclar aktivite seviyesi yüksek olarak gruplanmıştır.

\section{Stroop Görevi}

John Ridley Stroop (1935) tarafından geliştirlen Stroop görevi dikkat ve yönetici işlevleri test eden bilişsel bir görevdir. Stroop görevinde katılımclara aynı ya da farklı mürekkep renkleri ile yazılan renk isimlerini dikkate almamaları ve mürekkep rengine en kısa sürede tepki vermeleri istenir. Bu görevde mürekkep rengi ile yazı rengi uyumsuz olduğunda (Şekil 1b), uyumlu olduğu duruma oranla tepki sürelerinin daha yavaş olduğu gözlemlenmiştir. Stroop görevinde metnin ismi mürekkebin rengine verilen tepkiyi ketleyerek tepki süresinde gecikmeye sebep olur. Literatürde Stroop Etkisi olarak adlandırılan bu fenomen, uyumsuz koşuldaki tepki süresi ile uyumlu koşuldaki tepki süresi arasındaki fark olarak tanımlanmıştır. Stroop Etkisi bilgi işleme hızı ve yönetsel fonksiyonların etkililiği hakkında güçlü bir yordayıcı olarak kabul edilir (MacLeod, 1991). 
Bu görev 16 pratik deneme ve 272 deneysel deneme olmak üzere toplam 288 denemeden oluşmaktadır. 150 deneme ve daha fazla yapan katılımclar analize dahil edilmiştir. Her bir deneme 500 ms odaklanma noktasının ekranın ortasında belirmesi ile başlatılmıştır. Daha sonra mürekkep rengi uyumlu ya da uyumsuz olan bir renk ismi ya da renkli bir dikdörtgen (kontrol kondüsyonu) ekranın ortasında belirmiş, katılımclardan mürekkep renklerinin ilk harfine klavye üzerinde en kısa sürede basmaları istenmiştir. Doğru tepki veren katılımcılara pozitif geribildirim ('::') yanlıs tepki veren katılımclara ise negatif geri bildirim $\left.\left({ }^{\prime}:\right)^{\prime}\right) 200 \mathrm{~ms}$ boyunca gösterilmiştir. Geribildirimin verilmesinden $500 \mathrm{~ms}$ sonra yeni deneme başlamıştır. Her 16 denemede, katılımcılara tepki süreleri ve ortalama performansları hakkında geri bildirim verilmiş ve katılımcların ara vermelerine izin verilmiştir. Görev OpenSesame (Mathôt ve ark., 2012) kullanılarak hazırlanmıştır.

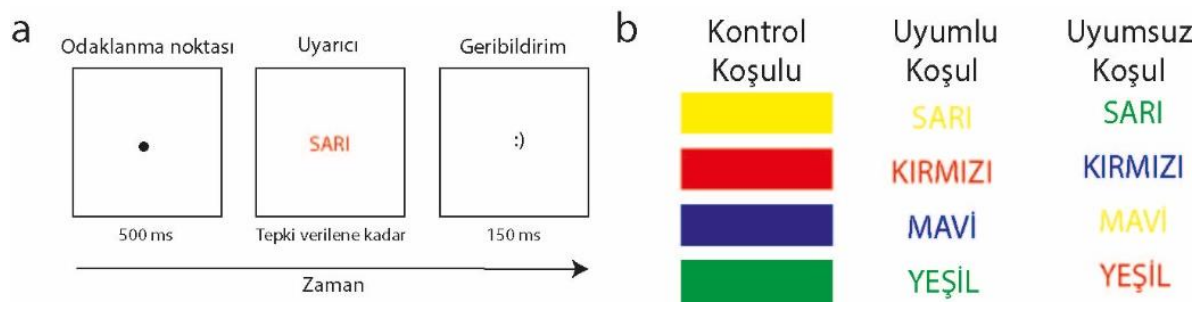

Şekil 1. Stroop görevi ve koşulları. a Deneysel deneme. b deneysel koşullar ve kullanilan uyarcilar.

Kontrol ve uyumlu koşul bütün olası uyarıcıları gösterir. Ancak uyumsuz koşulda yalnızca her bir renk isminin mürekkep renginin uyumsuz olduğu yalnızca bir koşul gösterilmiştir. Deneyde bütün olası koşullar eşit miktarda kullanılmıştır.

Bu çalışmada üç koşulu olan klasik bir Stroop görevi kullanılmıştır. Uyumlu koşulda renk ismi ve renk mürekkebi eşleşmektedir (Şekil 1b). Uyumsuz koşulda ise renk ismi ile renk mürekkebi eşleşmez. Uyumsuz koşulda renk isimleri ve olası eşleşmeyen bütün mürekkep renkleri eşit sayıda kullanılmıştır. Kontrol koşulda ise yalnızca mürekkebin olduğu bir kutu kullanılmıştır. Çalışmada kırmızı, sarı, yeşil ve mavi olmak üzere dört renk kullanılmıştır. 
Pratik denemeler analize dahil edilmemiştir. Analiz doğru tepki oranı ve süresi üzerinden yapılmıştır. Doğru tepki oranı toplam doğru sayısının, toplam deneme sayısına bölümü sonucunda hesaplanmıştır. Tepki sürelerinde ise yalnızca Stroop Etkisi üzerinde analiz yapılmıştır. Tepki sürelerinin analizinden önce, 100 ms'den kısa ve 2 sn'den uzun olan tepki süreleri filtrelenmiştir. Tepki süresi analizinde yalnızca doğru verilen tepkiler kullanılmıştır. Stroop Etkisi uyumlu koşuldaki tepki süresinin uyumsuz koşuldaki tepki süresinden çıkartılmasıyla hesaplanmıştır. Düşük değerler daha hızlı bilgi işleme hızına ve efektif yönetsel fonksiyonlara işaret eder.

İşlem: UFAA ve Stroop görevi OpenSesame kullanılarak hazırlanmıştır. OpenSesame' de hazırlanan görev JATOS sunucuları üzerinden katılımc1lara dağıtılmıştır Katılımcılar çalışmayı kendi ev bilgisayarlarında başlatmışlardır. Görevin başında cinsiyet, yaş, eğitim seviyesi ve medeni durumu içeren demografik formu yanıtlamış, sonrasında UFAA ölçeğini doldurmuşlardır. Akabinde Stroop görevi başlamıştır. Deney ortalama 12 dakika sürmüştür. Bu çalışma Medipol Üniversitesi Gelişimsel Olmayan Klinik Araştırmalar Etik Kurulu tarafından onaylanmıştır (793, 23/10/2019). Katilimcilar online veri toplama kitini doldurmadan önce gönüllü onam formunu doldurmuşlardır. Bir katılımcının aynı ağdan iki kere çalışmaya katılması teknik açıdan mümkün değildir. Kullanılan online platform buna izin vermemektedir.

Bu çalışma korelasyonel desende yürütülmüş betimsel bir çalışmadir. Verilerin analizinde nicel yöntemler kullanılmıştır.

Analiz: Fiziksel aktivite seviyesinin (FAS) doğru tepki oranına etkisini ölçmek için 3 (Fiziksel aktivite seviyesi: düşük, orta, yüksek) x 3 (Koşul: kontrol, uyumlu, uyumsuz) ANOVA analizi uygulanmıştır. Gereklilik dahilinde Greenhouse-Geisser düzeltmeleri uygulanmıştır. Stroop Etkisi hesaplandıktan sonra bu etki üzerinde 3 faktörlü (Fiziksel aktivite seviyesi) ANOVA analizi yapılmıştır. MET değerleri ile stroop etkisi arasındaki korelasyon da analize dahil edilmiştir. Stroop Etkisi ve MET değerlerinin analizlerinde negatif Stroop değeri olan katılımcılar filtrelenmiştir. Analiz için JASP 0. 14. 1.0 (Jasp, 2018) kullanılmıştır. 


\section{Bulgular}

\section{FAS'ın Stroop görevindeki doğru tepki oranına etkisi}

ANOVA sonuçları görev koşulunun doğru tepki oranına anlamlı etkisi olduğunu göstermiştir, F $(2,146)=26.05, p<.01$ (Şekil 2a). Kontrol ve uyumlu koşuldaki doğru tepki oranı uyumsuz koşula göre daha yüksektir (Tablo 2). Beklenen Stroop efektinin gözlemlenmesi, internet üzerinden yapılmasına rağmen deneyin geçerli ve güvenilir olduğuna işaret etmektedir. Fiziksel aktivitenin temel etkisiyle fiziksel aktivite ve görev koşulunun ortak etkisinin doğru tepki oranına anlamlı etkileri yoktur $(\mathrm{F}<1.2)$.

Tablo 2. Her bir koşul için doğru tepki oranları ortalama ve standart sapma değerleri

\begin{tabular}{lllll}
\hline Koşul & Fiziksel Aktivite & Ort & Sd & n \\
\hline Kontrol & Düşük & 0.943 & 0.109 & 33 \\
& Orta & 0.923 & 0.146 & 34 \\
Uyumlu & Yüksek & 0.965 & 0.029 & 9 \\
& Düşük & 0.948 & 0.105 & 33 \\
& Orta & 0.919 & 0.171 & 34 \\
Uyumsuz & Yüksek & 0.979 & 0.028 & 9 \\
& Düşük & 0.854 & 0.132 & 33 \\
& Orta & 0.817 & 0.182 & 34 \\
\hline
\end{tabular}

Ort. = Ortalama Doğru Tepki Orani; Sd = Standart Sapma, $n=$ Gözlem Sayısı

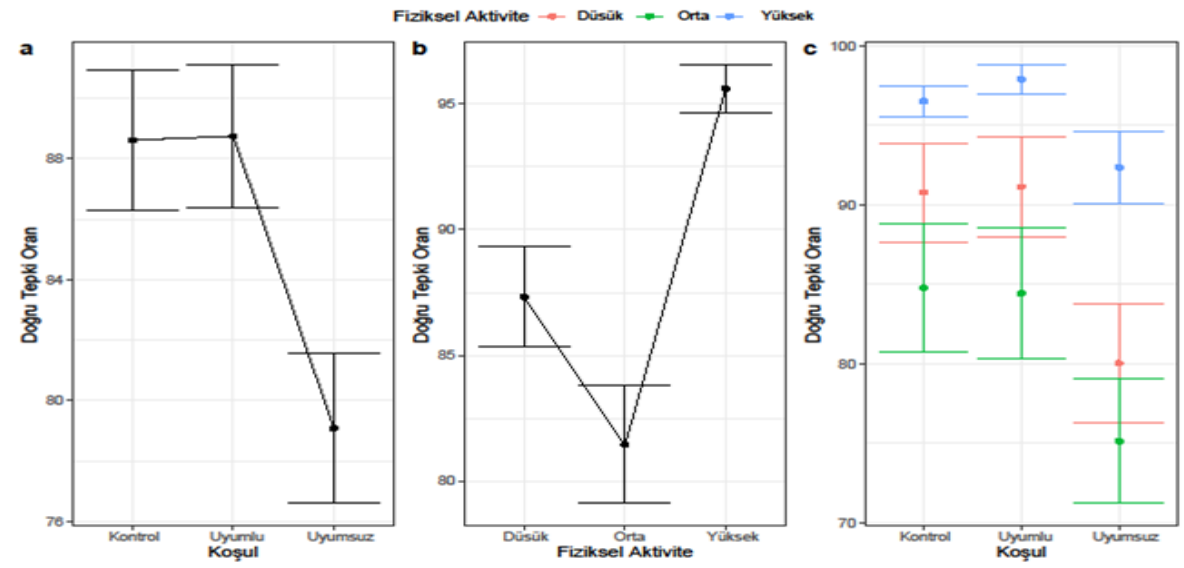

Şekil 2. Stroop görevindeki doğru tepki oranının koşullara göre değişimi. 
$\mathrm{Y}$ axis doğru tepki oranını yüz üzerinden gösterir. $\mathrm{X}$ axis a koşulu $\mathrm{b}$ fiziksel aktivite miktarını c koşulu gösterir. Hata çubukları ortalama hataya işaret eder.

FAS'ın Stroop Etkisi ile ilişkisi: ANOVA testi sonucunda Stroop Etkisi fenomeni uyumsuz koşulda tepki sürelerinin anlamlı olarak gecikmesi ile gözlemlenmiştir, $\mathrm{F}(2,146)=276.60, \mathrm{p}<.001$ (Şekil 3a). Kontrol ve uyumlu koşulda tepki süreleri uyumsuz koşula göre daha hızlıdır. Fiziksel aktivitenin Stroop efekte etkisi anlamlı değildir, ( $<$ < 1.2) (Şekil 3b). MET ile Stroop Etkisi arasındaki ilişkiye bakıldığında MET arttıkça Stroop Etkisinin azalma eğilimi gösterdiği gözlemlense de, bu ilişki anlamlı değildir (r $=-0.11, \mathrm{p}=0.35$ ) (Şekil 3c).

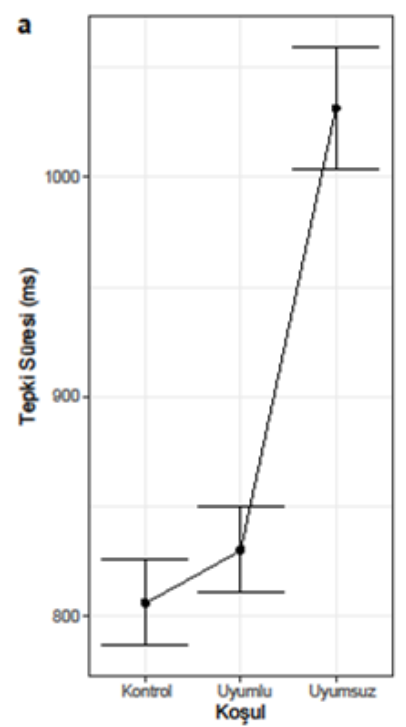

Fiziksel Aktivite " Düşūk * Orta * Yüksek
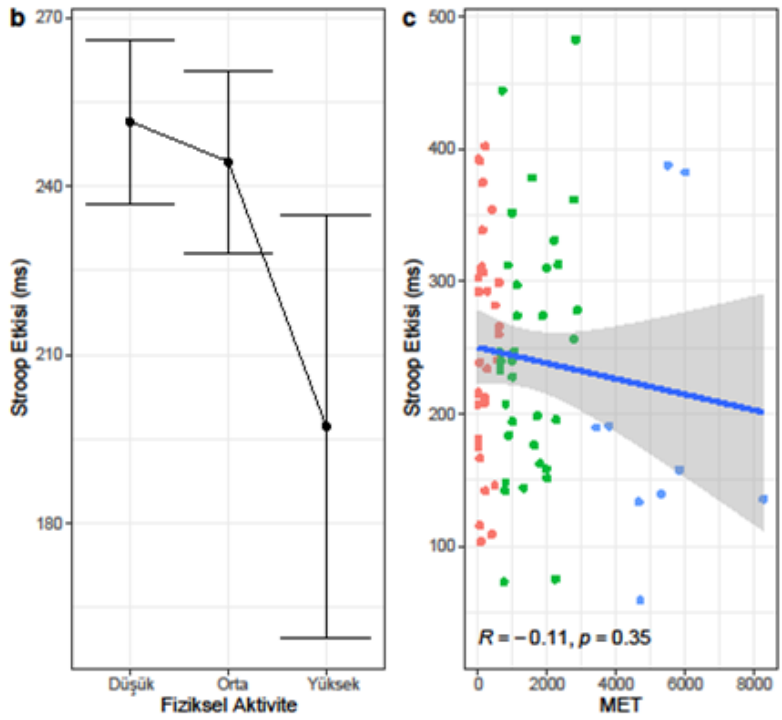

Şekil 3. Stroop etkisinin koşullara göre değişimi.

$\mathrm{Y}$ axis tepki süresini ya da stroop efekti ms olarak gösterir. $\mathrm{X}$ axis a koşulu b fiziksel aktivite miktarını c MET değerini gösterir. Hata çubukları ortalama hataya işaret eder. 


\section{Tartışma ve Sonuç}

Çalışmamızda 18-25 yaş arası üniversite öğrencilerinin fiziksel aktivite seviyeleri ve Stroop Testi kullanarak yaptığımız kognitif performansları arasındaki ilişki değerlendirilmiş doğrusal bir korelasyon belirlenememiştir. Bunun sebepleri örneklem sayısındaki yetersizlik ve grupların homojen dağılmaması olarak değerlendirilebilir . Durgut ve arkadaşlarının 30 lisans öğrencisi ile Fiziksel Aktivite Anketi Kısa Formu ve Stroop Testi kullanarak yaptıkları araştırmada benzer şekilde doğrusal bir korelasyon bulmamışlar ve katılımcı sayısının yetersiz olması kısıtlılığını bildirmişlerdir (Etnier vd., 2006). Bunun yanında, verinin toplandığ1 dönemde Türkiye'de Covit 19 Pandemisi nedeniyle sokağa çıkma kısıtlaması olması da bu sonuçların elde edilmesinde etkili olabilecek başka bir değişken olabilir. Benzer çalışmaların tekrarlanması önerilmektedir.

Çalışmamızda olguların fiziksel aktivite seviyelerini belirlemek için kullandığımız anket yönteminin subjektif verilere dayalı olması da korelasyonun sonucunu etkilemiş olabilir. Benzer şekilde, Etnier ve arkadaşları da çocuk, genç, yaşlıları kapsayan derlemelerinde kognitif performans ile fiziksel aktivite seviyesi negatif korelasyonunda, kullanılan ölçüm yöntemi farklılıklarının etkisi olabileceğini bildirmişlerdir (Padulo vd., 2019).

Literatürde Bayar ve Çakaloğlu (2018)özellikle çocuk ve yaşlılarla ilgili derlemelerinde, Kargün ve Baş (2016) ise üniversite öğrencileri ile yaptıkları çalışmada; subjektif anket sonuçlarının yanısıra deneysel olarak düzenli egzersiz ve sportif aktiviteler akabinde monitör veya cihazlarla yapılan objektif olçümler sonucunda olumlu etkiler bildirmişlerdir (Aslan vd., 2007; Bayar ve Çakaloğlu, 2018; Kargun vd., 2016). Bu çalışmada kognitif performans değerlendirmesinde Stroop Testi kullanılmıştır. Literatürde ise Chu ve arkadaşları 30 dakikalık orta şiddetli aerobik egzersiz sonrasında Stroop Testi kullanılmış, pozitif etki bildirmişlerdir (Chang vd., 2012). Bayar ve arkadaşları araştırmalarında değişik dozdaki egzersiz eğitimleri akabinde bireylerin kognitif fonksiyonlarında anlamlı gelişme vurgulamış olup kognitif fonksiyon üzerindeki kısa süreli ve orta şiddette egzersiz etkilerini inceleyen çalışmalar genellikle faydalı etkiler bildirmektedir. Egzersiz müdahalelerinin süresi kognitif değerlendirmelerin zamanlaması; egzersiz sonrası ve sırasında gibi faktörler ve egzersiz yöntemi ve yoğunluğu sonuçları etkilediği belirtilmektedir (Basso ve Suzuki, 
2017; Bayar ve Çakaloğlu, 2018; Chang vd., 2015; Chang vd., 2012; Lambourne ve Tomporowski, 2010). Bu çalışmada katılımcıların fiziksel aktivite seviyelerinin belirlenmesinde kullanılan Fiziksel Aktivite Kısa Anketi'nin beyana dayalı subjektif bir yöntem olması da ayrı bir etken olabilir. Bu nedenle gözlem altında deneysel çalışmalar yapılması daha objektif sonuçlar sağlayabilir.

Benzer örneklem ve benzer ölçümlerle, sokağa çıkma kısıtlaması uygulanmayan bir zamanda çalışma yenilenebilir. Aynı zamanda, veriler online platformda toplanmıştır. Katılımcların doğrudan bilgisayar üzerinden bilişsel görevleri yapabilecekleri çalışmalar yapılabilir. Bu çalışmanın en önemli sınırlılıkları, öncelikle verilerin sokağa çıkma kısıtlaması sürecinde toplanması ve ikinci olarak da verilerin online şekilde toplanması olarak belirtilebilir.

Sonuç olarak bu çalışmada üniversite öğrencilerin fiziksel aktivite seviyeleri ile kognitif performansları arasında doğrusal bir korelasyon belirlenememiştir. Ancak fiziksel aktivitenin sağlık üzerindeki olumlu etkileri bilimsel araştırmalarla kanıta dayalıdır. Ülkemizdeki genç, nüfusun çoğunluğu göz önüne alındığında bu çalışma ile fiziksel aktivitenin önemine dikkat çekerek genel toplum sağllğının korunmasına ve özellikle okul dönemindeki genç bireylerin bilişsel kapasitesinin geliştirilmesine etkisine vurgu yapılarak ,eğitim-öğretim hayatında verim ve başarının arttırılmasına fayda sağlama amaçlanmıştır. Bu konuda daha fazla olgunun dahil edildiği daha ileri çalışmalara ihtiyaç vardır. 


\title{
EXTENDED ABSTRACT
}

\section{Investigation of the Relationship between Physical Activity and Cognitive Performance in Young Adults}

\author{
Bağdat Tekkuş \\ İstanbul Medipol University
}

Modern life and advancing technological developments not only make life easier, but also bring with a negativity such as increasing inactivity. Inactivity and not doing sports mean a decrease in physical activity in all parts of society. As a result, with advancing age, diseases including cardiovascular diseases, obesity, Type II diabetes, hypertension, osteoarthrosis, osteoporosis, and some types of cancer may manifest themselves.

In addition to the effects mentioned above, cognitive functions are also affected by physical activity. When the literature is reviewed, it is seen that there are many studies conducted with children and elderly groups on the relationship between physical activity and cognitive functioning. However, studies examining this relationship in young adults are limited.

It has been proven by studies that physical activity has positive effects on both our physical and psychological health. However, it has an important place in the development of cognitive functions in every age group.

Studies on the correlation between physical activity level and cognitive function also show differences in terms of the tested aspect of cognitive function and test method (Etnier et al., 2006; Padulo et al., 2019). In recent studies, academic achievement is considered as an indicator of cognitive functions.

In this study, it was aimed to reveal the correlation between the physical activity levels and cognitive performance of university students between the ages of 18-25, and it was also aimed to raise social awareness about physical activity in our country, and to emphasize physical activity as a factor that supports success in education life and to encourage research on this subject. 
For this purpose, a total of 83 volunteer participants, 55 women and 28 men, were included in the study. The ages of the participants vary between 18-25. The International Physical Activity Questionnaire (IPAQ), developed by Craig et al. (2003), was applied to measure the physical activity levels of the participants. In addition, using the Stroop task developed by John Ridlet Stroop (1935), inferences were made about the speed of information processing and the effectiveness of managerial cognitive functions.

Participants started the tasks on their personal computers. Before the task, participants are expected to respond to the demographic information form. After the demographic form, the IPAQ scale was filled and then the Stroop task was completed.

This study is a descriptive study conducted in a correlational design. Quantitative methods were used in the analysis of the data. 3×3 ANOVA analysis was used to measure the effect of physical activity level on correct response rate. Greenhouse-Geisser corrections have been applied as required. After calculating the Stroop effect, a 3-factor ANOVA analysis was performed on this effect. The correlation between MET values and the stroop effect was also included in the analysis. In the analysis of the Stroop effect and MET values, participants with negative stroop values were filtered out. JASP 0.14. 1.0 (Jasp, 2018) was used for analysis.

ANOVA results show that the task condition has a significant effect on the correct response rate. The correct response rate in the control and congruent condition is higher than the incongruent condition. Observation of the expected Stroop Effect indicates that the experiment is valid and reliable, even though it was conducted over the Internet. The main effect of physical activity and the joint effect of physical activity and task condition do not have a significant effect on the correct response rate.

As a result of the ANOVA test, the Stroop Effect phenomenon was observed with a significant delay in response times in the incongruent condition. Response times in the control and congruent condition are faster than in the incongruent condition. The effect of physical activity on the stroop effect is not significant. Considering the relationship between MET and Stroop Effect, it is observed that the Stroop Effect tends to decrease as MET increases, but this relationship is not significant. 
As a result, a linear correlation could not be determined in the relationship between the physical activity levels of university students aged 18-25 and their cognitive performance evaluated using the Stroop Test. The inadequacy in the number of samples and the non-homogeneous distribution of the groups may have led to this result.

In the study, the questionnaire method used to determine physical activity levels is based on subjective data. This may have affected the correlation results. In this context, we recommend conducting experimental studies under observation, as it may yield more objective results.

The most important limitations of this study can be mentioned, firstly, the collection of data during the curfew and secondly, the collection of data online. With similar samples and similar measurements, the study can be renewed at a time when there is no curfew. Instead of collecting data on online platforms, studies can be conducted with tasks that the participants can complete directly on the computer.

As a result, in this study, a linear correlation could not be determined between the physical activity levels of university students and their cognitive performance. However, the positive effects of physical activity on health are based on scientific research and evidence. Further studies involving more cases are needed on this subject.

\section{Kaynakça / References}

Acevedo, A. and Loewenstein, D. A. (2007). Nonpharmacological cognitive interventions in aging and dementia. Journal of Geriatric Psychiatry and Neurology, 20(4), 239-249. https://doi.org/10.1177/0891988707308808.

Ardiç, F. (2014). Egzersizin Sağlık Yararları. Turkiye Fiziksel Tip ve Rehabilitasyon Dergisi, 60(September), 9-S14. https://doi.org/10.5152/tftrd.2014.33716.

Aslan, U. B., Livanelioğlu, A. ve Aslan, Ş. (2007). Fiziksel aktivite düzeyinin üniversite öğrencilerinde iki farkl yöntemle değerlendirilmesi. 18(1), 11-19.

Bamidis, P. D., Vivas, A. B., Styliadis, C., Frantzidis, C., Klados, M., Schlee, W., Siountas, A. and Papageorgiou, S. G. (2014). A review of physical and cognitive interventions in aging. Neuroscience \& Biobehavioral Reviews, 44, 206-220. https://doi.org/10.1016/j.neubiorev.2014.03.019. 
Basso, J. C. and Suzuki, W. A. (2017). The Effects of Acute Exercise on Mood, Cognition, Neurophysiology, and Neurochemical Pathways: A Review. Brain Plasticity, 2(2), 127-152. https://doi.org/10.3233/BPL160040.

Bayar, P. ve Çakaloğlu, E. (2018). Çocuklar üzerinde yapılan çalışmalar çerçevesinde aerobik egzersiz, fiziksel aktivite ve yönetici işlevler. Spormetre Beden Eğitimi ve Spor Bilimleri Dergisi, 16(2), 6-15.

Bilgin, E., Bulca, Y. ve Demirhan, G. (2020). Fiziksel Aktivite Düzeyi, Fiziksel Uygunluk, Akademik Basari ve Akademik Benlik Kavrami Arasindaki Iliskinin Incelenmesi. Egitim ve Bilim, 45(202), 311-325. https://doi.org/10.15390/EB.2020.8343.

Chang, Y., Chu, C., Wang, C., Wang, Y., Song, T., Tsai, C. and Etnier, J. L. (2015). Dose-Response Relation between Exercise Duration and Cognition. Medicine $\mathcal{E}$ Science in Sports $\mathcal{E}$ Exercise, 47(1), 159-165. https://doi.org/10.1249/MSS.0000000000000383.

Chang, Y. K., Labban, J. D., Gapin, J. I. and Etnier, J. L. (2012). The effects of acute exercise on cognitive performance: A meta-analysis. Brain Research, 1453, 87-101. https://doi.org/10.1016/j.brainres.2012.02.068.

Craig, C.L., Marshall, A.L., Sjöstörm, M., Bauman, A.E., Booth, M.L., Ainsworth, B.E., Pratt, M., Ekelund, U. and Yngve, A. (2003). International physical activity questionnaire (IPAQ): A comprehensive reliability and validity study in twelve countries. Medicine and Science in Sport and Exercise, 35(8), 1381-1395.

Ergun, M. (2013). Yaşlılık ve Egzersiz. Spor Hekimliği Dergisi, 48(4), 131-138.

Etnier, J. L., Nowell, P. M., Landers, D. M. and Sibley, B. A. (2006). A metaregression to examine the relationship between aerobic fitness and cognitive performance. Brain Research Reviews, 52(1), 119-130. https://doi.org/10.1016/j.brainresrev.2006.01.002.

Kargun, M., Togo, O. T., Biner, M., Pala, A. ve Kizar, O. (2016). Üniversite Öğrencilerinin Fiziksel Aktivite Düzeylerinin İncelenmesi. Spor Bilimleri Dergisi, 1(1), 61-61. https://doi.org/10.22396/sbd.2016.6.

Lambourne, K. and Tomporowski, P. (2010). The effect of exercise-induced arousal on cognitive task performance: A meta-regression analysis. Brain Research, 1341, 12-24. https://doi.org/10.1016/j.brainres.2010.03.091

Padulo, J., Bragazzi, N. L., De Giorgio, A., Grgantov, Z., Prato, S. and Ardigò, L. P. (2019). The Effect of Physical activity on cognitive performance 
in an italian elementary school: Insights from a pilot study using structural equation modeling. Frontiers in Physiology, 10, 1-9. https://doi.org/https://www.frontiersin.org/articles/10.3389/fphys.2019.00202/full.

Öztürk, M. (2005). Üniversitede eğitim-öğretim gören öğrencilerde uluslararası fiziksel aktivite anketinin geçerliliği ve güvenirliği ve fiziksel aktivite düzeylerinin belirlenmesi. Yüksek lisans tezi. Hacettepe Üniversitesi, Sağlık Bilimleri Enstitüsü, Ankara.

Savci, S., Öztürk, M., Arikan, H., Ince, D. I. ve Tokgözoğlu, L. (2006). Üniversite öğrencilerinin fiziksel aktivite düzeyleri. Turk Kardiyoloji Dernegi Arsivi, 34(3), 166-172.

Wang, C. K. J. and Biddle, S. J. H. (2001). Young People's motivational profiles in physical activity: A cluster analysis is there on a graduate scholarship from nanyang technical university in Singapore. Exercise Psychology Journal of Sport \& Exercise Psychology, 23, 1-23.

Stroop, J. R. (1935). Studies of interference in serial verbal reactions. Journal of Experimental Psychology, 18(6), $643-$ 662. https://doi.org/10.1037/h0054651.

MacLeod, C. M. (1991). Half a century of research on the Stroop effect: An integrative review. Psychological Bulletin, 109(2), 163-203. https://doi.org/10.1037/0033-2909.109.2.163.

Mathôt, S., Schreij, D. and Theeuwes, J. (2012). OpenSesame: An open-source, graphical experiment builder for the social sciences. Behavior Research Methods, 44(2), 314-324. doi:10.3758/s13428-011-0168-7.

\section{Kaynakça Bilgisi / Citation Information}

Tekkuş, B. (2021). Genç yetişkinlerde fiziksel aktivite ve bilişsel performans arasındaki ilişkinin incelenmesi. OPUS-Uluslararası Toplum Araştırmaları Dergisi, 18(42), 5699-5714. DOI: 10.26466/opus. 932629. 